\title{
Implicações de um processo Formativo de professores mediado por filmes, na constituição de uma visão ampliada de Saúde
}

\author{
Implications of a Training Process for Teachers mediated by films, in the \\ Constitution of an expanded Health vision
}

\author{
Eliane Gonçalves dos Santos (santoselianegoncalves@gmail.com) \\ Universidade Federal da Fronteira Sul, UFFS
}

\begin{abstract}
Maria Cristina Pansera de Araújo (pansera95@gmail.com)
Universidade Regional do Noroeste do Rio Grande do Sul, UNIJUI
\end{abstract}

Resumo: A formação de professores da área de Ciências da Natureza e a Saúde constitui, hoje, um campo de discussão e desafios ao ensino, porque os professores têm, geralmente, pouco conhecimento sobre as abordagens atuais em Saúde e em Educação em Saúde (ES). Daí a importância de pensar e repensar a formação em ES. Esta investigação é um recorte da pesquisa de doutorado. O objetivo foi investigar as implicações decorrentes de um processo formativo de professores mediado pelo uso de filmes comerciais, para a constituição de aprendizagens de uma visão ampliada de Educação em Saúde. A pesquisa é de natureza qualitativa, e teve como aporte teórico a abordagem histórico-cultural de Vigotski (2008), com a qual se buscou promover a elaboração, reelaboração e evolução conceitual do conhecimento (saúde) com um grupo de professores em formação inicial e continuada. O processo ocorreu durante oito meses, em sessões com filmes comerciais utilizadas para provocar a discussão e reflexão sobre saúde. Os dados coletados foram organizados em episódios, identificados em três categorias. A partir dos resultados foi possível reconhecer os indícios das implicações das interações vivenciadas pelos professores, em que um novo conhecimento pedagógico do conteúdo de saúde foi significado e (re)elaborado pelo grupo.

Palavras-chave: Constituição docente; processos interativos; cinema e educação; ensino de ciências; formação de professores.

\begin{abstract}
The training of teachers in the area of Natural Sciences and Health is now a field of discussion and challenges to teaching, because teachers generally have little knowledge about current approaches in Health and Health Education (HE). Hence the importance of thinking and rethinking education in Health Education. This investigation is an excerpt of the doctoral research. The objective was to investigating the implications related to the formation process of Nature Science teachers, intermediated by the use of advertisement movies to the development of learning the big view of Education and Health. This research is qualitative and the theoretical approach used is the historical-cultural approach by Vigotski (2008), with which it sought to promote the development, the rework and the conceptual evolution of knowledge (health) with a group of teachers in initial and continuing formation. This formation
\end{abstract}

Recebido em: 26/08/2020

Aceito em: $1 \% / 12 / 2020$ 
process took place during eight months in movies sections with advertisement used to cause discussion and reflection about health. The descriptive the organization in episodes, identified by three categories. Throughout this result, it was possible to know the evidences of the implications in interaction experienced by teachers, in which the new pedagogical knowledge of health content was significant and reelaborated by the group.

Keywords: Teachers Formation; interaction process; cinema and education; science teaching; teacher training.

\section{A NECESSÁRIA DISCUSSÃO SOBRE A EDUCAÇÃO EM SAÚDE NO PROCESSO FORMATIVO E NA PRÁTICA DOCENTE DO PROFESSOR}

Falar da formação de professores implica reconhecer as expectativas e os desafios contidos na docência, e remete a pensar nos limites de um ensino pautado nas necessidades reais dos professores e dos alunos. Significa repensar um ensino que rompa com a perspectiva reproducionista, linear, dicotômica e do isolamento profissional. A docência é um campo que enseja debates, transformações e tomada de decisões. Nesse aspecto, além de reflexões sobre a profissão, as práticas pedagógicas, há de se pensar os conteúdos curriculares. No ensino de Ciências, como apontam Martins (2017), Mohr (2002), Zancul e Costa (2012), uma temática que merece estudos e reflexões é Saúde e a Educação em Saúde (ES).

A questão central da abordagem da ES na escola refere-se a sua apresentação como mera ausência de doenças, numa visão biomédica, que pouco contribui com uma formação de "hábitos saudáveis e na consolidação de uma visão mais ampla e crítica de saúde, no entanto, para isso, os educadores necessitam ter formação e conhecimento suficientes" (ZANCUL; COSTA, 2012, p. 68). Nesse sentido, essa temática tem sido referência nas pesquisas de âmbito nacional e internacional, nos últimos anos (CARVALHO; JOURDAN, 2014; MARTINS, 2017; MOHR, 2002).

O presente artigo discorre sobre as interações, os caminhos formativos e a compreensão de saúde de professores em formação inicial (FI) e continuada (FC) que participaram de um grupo colaborativo, pois como afirma Vigotski (2008) o homem é um ser que se constitui, se apropria e elabora conhecimentos, sempre mediados pelo outro, na e pela linguagem e interações sociais. Desta maneira, a discussão entre pares, o trabalho formativo e colaborativo entre professores, possibilita que se avance em direção a uma formação que contemple a reflexão epistemológica, a autonomia

Recebido em: 26/08/2020

Aceito em: $1 \% / 12 / 2020$ 
profissional, e a apropriação do caráter social, cultural e histórico da construção do conhecimento.

A pesquisa apresentada neste artigo, contou com a participação dos bolsistas do Subprojeto Programa Institucional de Bolsas a Iniciação à Docência - PIBID Ciências Biológicas da Universidade Federal da Fronteira Sul, Campus Cerro Largo/RS. Tendo como objetivo investigar as implicações decorrentes de um processo formativo de professores de Ciências da Natureza, mediado pelos filmes comerciais ${ }^{1}$, para a constituição de aprendizagens sobre uma visão ampliada de Educação em Saúde. Para tanto, foram utilizados os filmes comerciais como um instrumento pedagógico ${ }^{2}$ por vislumbrar seu grande potencial para a atividade de ensino, ao possibilitar discussões e reflexões sobre a Educação em Saúde, como um espaço profícuo de troca de aprendizagens, de "abertura e diálogo, para além das palavras" (ANTUNES, 2015, p. 12).

O artigo é um recorte da pesquisa de doutorado da primeira autora, e está organizado da seguinte maneira; i) um entrelaçamento entre as questões da formação de professores, Saúde e Educação em Saúde e o cinema; ii) encaminhamentos metodológicos da pesquisa; iii) as aprendizagens produzidas nas sessões fílmicas para educação em saúde, em processos formativos e iv) considerações finais.

\section{Formação de professores x educação em saúde}

O processo formativo é um campo de inúmeras pesquisas, debates e reflexões, as quais apontam a necessidade de discutir e re(pensar) a FI e FC de professores reflexivos e pesquisadores de sua prática, questões referentes às melhorias nos processos de ensino e de aprendizagem, a dicotomia entre a teoria e a prática, a iniciação à docência. Para Schön (1983), essas questões sinalizam a emergência de um processo formativo continuum $^{3}$ na vida profissional do professor. Compartilhando do mesmo pensamento, García (1995, p.54) aponta para a "necessidade de conceber a formação de professores (FP) sobre um continuum", que implica um ensino de melhor qualidade na licenciatura

\footnotetext{
${ }^{1}$ Entende-se como filmes comerciais aqueles que foram produzidos e comercializados com fins lucrativos, disponíveis em cinemas, canais de televisão entre outros.

${ }^{2}$ Entendo com Vigotski (2008) que os filmes são instrumentos que organizam o conhecimento e permitem significações, ou seja, um meio para desenvolver a ação mental, para pensar sobre determinadas questões e situações.

${ }^{3}$ Donald Schön (1983), concebe que a formação de professores é um processo contínuo, que está sempre acontecendo, e não acaba ao concluirmos a graduação.
}

Recebido em: 26/08/2020

Aceito em: $1 \% / 12 / 2020$ 
e, posteriormente, nos demais níveis de ensino, pois para "manter a qualidade de ensino [...] é preciso criar uma cadeia coerente de aperfeiçoamento, cujo primeiro nível é a formação inicial”(GARCÍA, 1995, p. 55).

Para tanto, algumas questões formativas necessitam ser revistas e analisadas. Principalmente as que se referem às dificuldades de cunho pedagógico que o futuro professor e o professor em exercício se deparam ao exercer seu métier, que, aliadas com a ausência ou um enfoque simplista de conteúdos durante sua formação, comprometem o seu fazer docente. Como exemplo de entendimento simplista de conteúdo, podemos citar os correlatos à Saúde, que na maioria dos cursos de Ciências Biológicas encontrase ancorado no modelo biomédico o que pouco ou nada contribui para que os professores desenvolvam sua prática e trabalhem em uma perspectiva que permita "ao aluno a reflexão sobre o conhecimento que está sendo desenvolvido para aproveitá-lo, de alguma forma, em sua própria rede conceitual” (MOHR, 2002, p. 41).

Referente a esta situação, amplia-se o debate em torno da reestruturação dos currículos escolares de Ciências da Natureza, em que um dos pontos centrais de discussão se relaciona à maneira de os professores em processo formativo ${ }^{4}$ conceberem a Ciência e o trabalho científico. E, como esta visão influencia suas práticas pedagógicas e as aprendizagens desenvolvidas pelos estudantes. Tais assuntos convidam à reflexão, uma vez que os conhecimentos científicos, escolares e cotidianos apresentam características singulares que, no decorrer da FP de Ciências da Natureza, devem ser compreendidas pelos sujeitos envolvidos.

Outra questão diz respeito à temática Saúde e Educação em Saúde, em que a visão biomédica de simples ausência de doença, numa perspectiva curativa, prevalece no ensino dos conteúdos escolares. Diante desse cenário, Knaut, Pontarolo e Carletto (2013) afirmam que mesmo a população tendo acesso às informações, pelos meios de comunicação acerca dos hábitos de vida saudável e modificações de estilo de vida, ainda são identificadas doenças crônicas não transmissíveis (DCNT), nas sociedades modernas. "Aliadas a este perfil, as questões culturais e comportamentais acentuam escolhas equivocadas e de pouca responsabilidade para com o desenvolvimento de hábitos saudáveis e cuidados com o próprio corpo" (KNAUT, PONTAROLO E CARLETTO, 2013, p. 2). 
No cenário educativo, a apresentação de alguns assuntos, na grande maioria das vezes, ocorre a partir de uma visão higienista dos conteúdos, presumindo que o processo de ensino está restrito a informações, prescrições e atitudes de mudanças de comportamento. Para Zancul e Gomes (2011, p. 51), “os atuais cursos de licenciatura em Ciências Biológicas, de uma maneira geral, têm formado professores sem adotar temas de Educação em Saúde nos seus conteúdos escolares”, o que compromete o ensino de saúde e as ações promotoras de saúde. Situação oposta ao que seria esperado em se tratando do ensino, o qual tem como objetivo o desenvolvimento de habilidades cognitivas, do raciocínio, da reflexão e do senso crítico.

Daí a necessidade de um ensino mais abrangente sobre saúde nos cursos de licenciatura e mais formações e discussões tanto em nível de FI quanto da FC para debater sobre o que de fato seja promoção da saúde e qualidade de vida, auxiliando os professores a pensar e elaborar atividades de ensino com "problemas que têm sentido na realidade dos estudantes, [...], problematizando os temas por meio de estratégias pedagógicas diversas, priorizando os valores e a aquisição de hábitos e atitudes com dimensões fundamentais" (SCHALL, 2010, p. 184).

Perante o exposto, e tendo a escola como espaço de formação social do sujeito, acredito, assim como Zancul e Gomes (2011), que os cursos de formação de professores, em particular os de Ciências e Biologia, precisam contemplar em suas disciplinas conhecimentos e valores que capacitem os professores a tratar de temas de Educação em Saúde na escola, a fim de promover e articular conhecimentos amplos do assunto e o desenvolvimento de possibilidades formativas geradoras de mudanças pessoais e sociais. Diante desta perspectiva, julgo ser importante educar os estudantes para a cidadania, pois no entendimento de Alarcão (2011, p. 25) "a sociedade não existe sem as pessoas que a constituem e a vão formando. Mas, por sua vez, está influencia a formação e atuação das pessoas. A escola é um setor da sociedade, é por ela influenciada e, por sua vez, influencia-a”.

Ao fazer essas defesas em relação à Educação em Saúde no processo formativo e na prática docente do professor, partilho com Mohr (2002, p. 38) do entendimento da expressão Educação em Saúde como "atividades realizadas como parte do currículo escolar, que tenham uma intenção pedagógica definida, relacionada ao ensinoaprendizagem de algum assunto ou tema relacionado com a saúde individual ou coletiva". 
Nesse sentido, para uma abordagem mais ampla, que contribua para a promoção da saúde e abandono dos entendimentos higienistas de saúde/doença, necessita haver uma retomada e discussão do que de fato é importante ensinar sobre Saúde na escola. Dessa forma, julgo pertinente que a formação inicial contemple essa discussão e busque um diálogo a fim de provocar mudanças de currículo, visando a uma formação que trate a Saúde dentro de uma abordagem sistêmica, que considera o sujeito em sua integralidade. Sob esse aspecto, "um dos grandes desafios da formação inicial é conjugar a solidez e competência de conhecimentos específicos com a capacidade de articulá-los em diferentes campos, com uma visão mais ampla, sistêmica e integrada" (VENTURINI; PEDROSO; MOHR, 2013, p. 2).

Partindo do entendimento da necessidade de um ensino de saúde ampliado na formação inicial, compreendo que a linguagem cinematográfica possibilita a abertura de espaços para o diálogo, a reflexão, a divergência de pensamentos e compreensões de certos assuntos, proporcionando aos sujeitos a produção de diferentes sentidos e significados. A imersão em outras realidades permite aos espectadores experimentar diferentes formas de ver, perceber, sentir e refletir sobre diversas temáticas, dentre elas a Educação em Saúde.

\section{Processo formativo: Educação em Saúde mediada pelos filmes comerciais}

O cinema na sala de aula possibilita discutir conhecimentos conceituais, temas e situações do cotidiano por meio das histórias narradas. A linguagem cinematográfica pode tornar-se um valioso dispositivo de aprendizagem, visto que estimula o aluno a pensar e falar sobre seus entendimentos e significações, tornando viável a instauração de novas formas de estar em sala de aula, proporcionando mudanças nesse espaço educativo.

Outro fator importante no trabalho pedagógico com os filmes é garantir uma abordagem além da experiência cotidiana, sem negá-la (NAPOLITANO, 2013). Para esse autor, o professor deve "propor aos alunos leituras mais ambiciosas além do puro lazer, fazendo a ponte entre emoção e razão de forma mais direcionada, incentivando o aluno a se tornar um espectador mais exigente e crítico, propondo relações de conteúdo/linguagem" (NAPOLITANO, 2013, p. 15).

Recebido em: 26/08/2020

Aceito em: $1 \% / 12 / 2020$ 
Para Chaves (2012, p. 87), “é importante pôr em debate e combater as diferentes narrativas históricas que circulam no campo social, investindo em uma formação para pensar, decidir e não para acatar”. Nesse sentido, o cinema pode ser um instrumento importante para contribuir com uma visão ampliada de Saúde e Educação em Saúde, pois a obra propicia ao seu espectador distinguir e desencadear um sistema de significação específico e distinto dos demais.

A atividade pedagógica mostra-se, então, envolta nesses desafios que conduzem à discussão e à reflexão como compromisso na arte de educar e (re)criar, em um contínuo processo de formação. Assim, a partir da abordagem histórico-cultural orientei a discussão sobre Saúde e Educação em Saúde com a mediação de filmes comerciais, como instrumento de apropriação e problematização pelos professores em processo formativo dialético, que

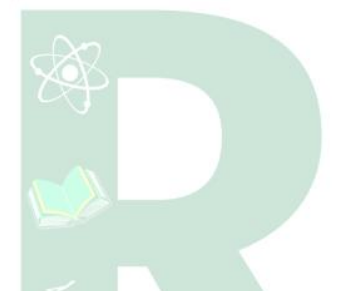

[...] se caracteriza, pelas transformações qualitativas de umas formas em outras, que configuram revoluções; pelo complexo entrecruzamento dos processos de evolução e involução; pelo entrelaçamento de fatores internos e externos; e pelo intrincado processo de adaptação e superação de dificuldades (FREITAS, 2001, p. 10).

Desta forma, busquei interligar o contexto formativo e o cinema, a partir da proposição de Vigotski de que "a natureza transforma-se em cultura, sem perder suas características, e a cultura materializa-se em natureza, constituindo um paradoxo que só o caráter simbólico da cultura pode desvendar" (PINO, 2005, p. 53). Assim,

[...] perceber e diferenciar as coisas, associar umas às outras, emitir e captar sinais que lhes permitam orientar suas ações, realizar escolhas de parceiros e compartilhar emoções (expressão de uma atividade cognitiva e social que lhes permite interagir com o seu meio e seus congêneres), o próprio do homem é conferir a todas essas funções uma significação, o que dá às atividades biológicas uma dimensão simbólica. Atribuir significação a essas funções não é destituí-las da sua condição natural, como atribuir significação as coisas não é destituí-las da sua condição material, mas torná-las funções e coisas humanas. Atribuir significação às coisas - as que o homem encontra já prontas na natureza e as que ele produz agindo sobre ela - constitui o que entendemos produzir cultura. Dessa forma, falar da relação entre funções biológicas e funções culturais significa falar de uma relação pela qual aquelas, sob a ação destas, adquirem uma dimensão simbólica, ou seja, uma nova forma de existência (PINO, 2005, p. 53-54).

Tais ideias permitem compreender que o desenvolvimento das funções mentais superiores está contido no pensamento, na linguagem, na consciência, na percepção, na memória, entre outros (PINO, 2005). De acordo com Vigotski, essas funções são ações mediadas, estabelecidas em relações que os homens têm entre si e com a natureza; dessa

Recebido em: 26/08/2020

Aceito em: $1 \% / 12 / 2020$ 
maneira, o biológico e o social não estão separados. Ele indica que a cultura é produção humana carregada de significação, ao passo que quando nos apropriamos dela estamos nos constituindo como seres culturais, e a inserção, neste universo, ocorre sempre por uma dupla mediação, a dos signos e a do outro, detentor de significação (VIGOTSKI, 2008).

Rego (1995, p. 50), fundamentada em Vigotski, apresenta os instrumentos, cuja função é regular os objetos e os signos "considerado aquilo (objeto, forma, fenômeno, gesto, figura ou som) que representa algo diferente de si mesmo. Ou seja, substitui e expressa ideias, situações e objetos, servindo como auxílio da memória e da atenção humana", tem papel essencial no processo de mediação, por proporcionar ao homem o contato, a intervenção e a transformação da natureza, mas principalmente por possibilitar um avanço evolutivo para a espécie humana.

Entendo com Vigotski (1929, 2008), que o cinema é um instrumento que serve para organizar o conhecimento, o signo (linguagem) e o pensamento. Desta maneira, o uso de filmes comerciais, no processo formativo de professores, caracterizou-se como instrumento que permitiu significações, um meio para desenvolver a ação mental, para pensar sobre determinadas questões e situações, que tangem à prática docente sobre a ES, no contexto escolar. Destaca-se que a mediação teve um papel preponderante nesta investigação, pois a atividade com os filmes foi uma ação planejada e intencional com o objetivo de provocar novos entendimentos e uma visão ampliada de saúde.

Assim, vislumbrei um processo de reflexão mediada e interativa entre pares, em que o diálogo formativo se apresentou como caminho para avançar nos sentidos atribuídos às questões de ES e à docência, conforme sinaliza Zeichner (2008). O diálogo formativo foi delineado e percorrido pela constituição do grupo colaborativo de trabalho em que a reflexão e a pesquisa da prática foram as molas propulsoras do processo.

Nesse sentido, pensando no contexto formativo de professores, busco as obras cinematográficas para fomentar discussões no ensino e possibilitar reflexões sobre a Educação em Saúde, como um espaço profícuo de trocas e aprendizagens, de "abertura e diálogo, para além das palavras" (ANTUNES, 2015, p. 12

O trabalho com filmes na escola pode ir aos poucos modificando a prática docente e as salas de aulas, contribuindo para "dar respostas a alguns dos problemas identificados nas escolas como dificuldade de comunicação entre adolescentes e 
professores, o desinteresse das crianças pelas atividades escolares e questões ligadas às diferentes capacidades de percepção e atenção" (DUARTE et al., 2004, p. 38). A seguir apresento o percurso metodológico realizado para o desenvolvimento da pesquisa.

\section{PERCURSO DA PESQUISA: ENCAMINHAMENTO METODOLÓGICO}

A pesquisa é de natureza qualitativa, e teve como aporte teórico a abordagem histórico-cultural de Vigotski (2008), com a qual se buscou promover a elaboração, reelaboração e evolução conceitual do conhecimento (saúde) com um grupo de professores em FI e FC. Desse modo, foi criado o contexto de intervenção experimental proposto por Vigotski (2008, 1929), que propõe três princípios: (1) processo, em que a análise implica considerar as mudanças do desenvolvimento humano, partindo da história das funções mentais superiores; (2) abordagem metodológica explicativa e não meramente descritiva, para revelar as relações dinâmicas, reais das relações internas construtivas dos fenômenos humanos e, (3) comportamentos automatizados, que têm na análise das origens um papel fundamental, visto que o processo é histórico e cultural.

O grupo contou com a participação de vinte e seis (26) licenciandos do curso de Graduação em Ciências Biológicas da Universidade Federal da Fronteira Sul (UFFS), do Programa Institucional de Bolsas de Iniciação à Docência, subprojeto Pibid-Ciências Biológicas, três (3) professores universitários formadores e cinco (5) professoras supervisoras do Pibid da escola pública de ensino.

O processo formativo ocorreu durante oito meses, em sessões com filmes comerciais utilizadas para provocar a discussão e reflexão sobre saúde (QUADRO 1). Nos primeiros e o último encontros, um em cada mês subsequente, a pesquisadora ficou responsável pela escolha dos filmes a serem assistidos; os três encontros seguintes ficaram sob responsabilidade do grupo, que selecionou e encaminhou a atividade com os filmes. A intenção desse encaminhamento foi motivar e instigar a interação. Após cada exibição, o grupo discutia os seus entendimentos acerca da temática em questão (saúde e educação em saúde), as possibilidades e dificuldades do trabalho pedagógico com filmes, entre outras questões. No Quadro 01, observa-se o cronograma de organização das sete sessões fílmicas.

Recebido em: 26/08/2020

Aceito em: $1 \% / 12 / 2020$ 
Quadro 01 - Cronograma das sessões fílmicas

\begin{tabular}{|c|c|c|}
\hline Encontros & Filme selecionado & Responsável pela escolha \\
\hline $\mathbf{1}^{\circ}$ & A vida de Louis Pasteur (1937) & Pesquisadora \\
\hline $\mathbf{2}^{\circ}$ & O Curandeiro da Selva (1992) & Pesquisadora \\
\hline $\mathbf{3}^{\circ}$ & O Óleo de Lorenzo (1993) & Pesquisadora \\
\hline $\mathbf{4}^{\circ}$ & O Jardineiro Fiel (2005); & Professores Formadores \\
\hline $\mathbf{5}^{\circ}$ & O Físico (2013) & Professores Supervisores Bolsistas Pibid \\
\hline $\mathbf{6}^{\circ}$ & Uma Prova de Amor (2009) & Licenciandos Bolsistas Pibid \\
\hline $\mathbf{7}^{\circ}$ & Divertida Mente (2015) & Pesquisadora \\
\hline
\end{tabular}

Fonte: Santos; Pansera-de-Araújo.

Os dados descritivos foram produzidos a partir dos questionários, diários de bordo, das gravações em áudio das discussões das sessões fílmicas e do grupo focal, que posteriormente foram degravadas. Após as transcrições e releituras dos registros obtidos, parte dos dados foi avaliada pela análise do seu conteúdo e os demais pela análise microgenética (GOES, 2000), que possibilitou a organização em episódios. Para Góes (2000, p. 9), “os episódios se constituem em recortes, mecanismos de apreensão e análise do percurso/movimento que sinalizam transformações pormenorizadas que sem contexto ficam impossíveis de serem compreendidas/aprendidas".

A partir desta análise nosso objetivo foi identificar que aprendizagens em educação em saúde são produzidas na discussão de filmes comerciais, em aulas da educação básica ou superior. Para resguardar o anonimato, a autoria e o sigilo dos participantes, nomes fictícios foram utilizados: professores supervisores começam com a letra "S" (Susana, Sabrina, Sofia, Sara e Selma); formadores com a letra "H” (Helena, Heitor, Hugo); e licenciandos com a letra "L" (Leandro, Lúcio, Lia, ..., Luana). A pesquisa foi submetida e aprovada no Comitê de Ética em Pesquisa. A seguir são apresentadas as categorias que emergiram da investigação com o grupo de professores.

\section{APRENDIZAGENS PRODUZIDAS NAS SESSÕES FÍLMICAS PARA EDUCAÇÃO EM SAÚDE, EM PROCESSOS FORMATIVOS}

Por meio dos resultados foi possível reconhecer os indícios das implicações das interações vivenciadas pelos professores no grupo de trabalho colaborativo, em que um novo conhecimento pedagógico do conteúdo de saúde foi significado e (re)elaborado pelo grupo. Da análise, emergiram três categorias, a saber: i) evolução das compreensões de Saúde e Educação em Saúde, no diálogo com professores no grupo

Recebido em: 26/08/2020

Aceito em: $1 \% / 12 / 2020$ 
colaborativo; ii) filmes comerciais como instrumento de reflexões sobre questões curriculares no processo formativo; iii) produção do conhecimento científico. Neste texto será apresentada uma síntese de cada uma das categorias.

i - Evoluções das compreensões de Saúde e de Educação em Saúde no diálogo com os professores em formação.

Ao longo da vida acadêmica e profissional, os professores estão em constante processo de aprendizagem. A formação continuada necessita ser um elemento central no percurso formativo, assim como a compreensão da relação entre teoria e prática. A participação em grupos colaborativos, a reflexão e o diálogo devem ser elementos-chave em um processo de formação continuada articulada a inicial, pois permite aos professores compreender a docência em um constante movimento, em que as interações entre pares e os diálogos formativos são necessários à qualificação da prática. Uma vez que a participação em grupos colaborativos propicia a circulação de novas ideias, assim como o compartilhamento de angústias, dificuldades das demandas cotidianas da sala de aula e tomada de decisões conjuntas, além de promover o contato com novos conhecimentos decorrentes de leituras, discussões e reflexões em grupo.

Ao analisar o percurso formativo, observo as especificidades do processo e as conexões estabelecidas. A reflexão coletiva e as interlocuções entre os professores em formação revelam a necessidade de um pensamento de saúde ampliado no ambiente escolar. Ao assumir esta questão como emergente, no processo vivenciado, apresento os episódios que emergiram do material analisado.

Durante muitos anos vigorou na sociedade - e consequentemente na escola - o entendimento de saúde a partir do modelo biomédico (SANTOS; WESTPHAL, 1999) e pouco se avançou nesta discussão no espaço acadêmico e escolar. Diante da lacuna na formação docente sobre a temática da saúde, trago as primeiras enunciações dos professores sobre o assunto, apresentadas nos episódios 01 e 02.

Episódio 01 - A compreensão de saúde na formação inicial ${ }^{5}$

Lara: As questões de saúde não possuem em nossa formação um enfoque, acredito que apenas são tratadas rapidamente dentro dos conteúdos.

${ }^{5}$ Os episódios e os excertos de escritas foram colocados no texto de forma destacada, em itálico, fonte 11 e recuo de $2 \mathrm{~cm}$.

Recebido em: 26/08/2020

Aceito em: $1 \% / 12 / 2020$ 
Selma:[...] muito precariamente, pois não me recordo desse contexto naquela época e no curso de Ciências Biológicas plena esse assunto era pouco abordado.

Heitor: Não foi discutido de nenhuma forma ao longo do curso. Não era temática e nem conteúdo do curso.

O episódio 01 provoca reflexões sobre a importância de uma retomada do ensino de saúde na formação inicial de professores. Os dizeres sinalizam a falta de abordagens do tema na formação, pois Selma já concluiu a graduação há 25 anos, Heitor há 16 anos e Lara é graduanda. As afirmações de Lara e de Heitor indicam que algo está errado no processo formativo, ou seja, há ausência de formação em ES nos cursos de graduação destes professores. Com base nas enunciações da licencianda e dos dois professores, foi possível compreender o porquê, durante a apresentação da proposta de pesquisa e discussão dos objetivos da tese, de muitos professores na sala ficarem confusos e inseguros com algumas questões do questionário. Quando analiso as escritas e falas das compreensões iniciais de saúde e como esse tema é ou foi abordado durante a formação, ficou claro que não era e nem é uma temática presente, nos currículos de graduação de Ciências Biológicas.

Assim como Lara, Selma e Heitor, os demais professores do processo formativo compartilham que a temática Saúde é pouco discutida, nos cursos de formação, sendo abordada dentro de um enfoque prescritivo, com ênfase no modelo biomédico, em que as discussões estão ancoradas nas doenças e agentes patológicos. Essa abordagem reduzida pouco contribui para um entendimento de saúde mais amplo, uma vez que os "conteúdos curriculares de ciências e biologia possuem grandes afinidades com os determinantes sociais que tornam abrangente a abordagem do tema saúde" (GUSTAVO; GALIETA, 2014, p. 4881). Aspectos como "habitação, alimentação, renda, meio ambiente, trabalho, transporte, emprego, lazer, liberdade, acesso a posse de terra e acesso a serviços de saúde” (BRASIL, 1986, p. 4) também são referenciados.

Ao evidenciar, no episódio 01, a ausência da discussão de saúde na formação inicial dos professores numa abordagem que considere a prevenção, a promoção da saúde, da melhoria das condições de vida e preservação do ambiente, reafirmo a importância desta investigação, no intuito de promover uma compreensão ampliada de Saúde com o grupo de professores. O episódio 02 apresenta as memórias dos licenciandos acerca dos conteúdos de saúde desenvolvidos, quando estudaram na escola básica.

Recebido em: $26 / 08 / 2020$

Aceito em: $1 \% / 12 / 2020$ 
Episódio 02 - Memórias dos licenciandos acerca dos conteúdos de saúde na escola

Lúcio: Lembro que tivemos aulas sobre vários temas de saúde, desde escovação correta dos dentes, até hábitos alimentares corretos.

Lis: Foram trabalhadas questões mais específicas como as doenças, o desenvolvimento de vacinas e curas para as mesmas, sem mostrar os processos evolutivos de todos esses acontecimentos.

Lena: A professora normalmente falava de algumas doenças, enfatizando como cuidar da saúde. Citava algumas doenças, precauções, sintomas a fim de esclarecer algumas dúvidas a respeito da doença.

Lúcia: De forma bastante rasa, superficial, com apresentações rápidas, decoradas e sem ajuda de profissionais.

Lara: Basicamente por meio de estudo das doenças, como AIDS, ou outras que estavam em "alta" no momento.

Liana: [...] apenas as doenças relacionadas à saúde pública, algumas vezes, em forma de pesquisa, outras vezes apenas nos era apresentada a doença, seus sintomas, forma de contágio e prevenção.

No episódio 02, é possível encontrar pistas sobre como os conteúdos foram abordados na escola. A maioria evidencia o enfoque prescritivo da saúde, com ênfase nas doenças, e daquelas que estavam em "alta" em um dado momento, os professores ministravam suas aulas apenas enfatizando os conteúdos a partir de uma visão restrita de saúde, ou seja, o modelo biomédico, e não uma Educação em Saúde formadora (MOHR, 2002). Este episódio ajuda a entender por que os licenciandos, ao serem indagados sobre seus entendimentos de saúde, ainda a compreendem apenas como ausência de doença. Nessas memórias, identifico outra questão quanto à ausência da formação de um sujeito em sua integralidade. Marinho e Silva (2015, p. 354) propõem, para que a ES tenha um caráter formador "[...] a noção de conteúdos necessita superar aquela visão restrita aos conhecimentos das disciplinas e ser ampliada para um entendimento de que os 'conteúdos' se configuram como tudo o que se tem que aprender para alcançar determinados objetivos".

Nessa perspectiva, chamo atenção aos dizeres de Lis, ao expressar que os conteúdos de saúde eram abordados sem mostrar os processos evolutivos de todos esses acontecimentos. A manifestação de Lis sinaliza a necessidade de contextualização do ensino, a fim de que o sujeito possa compreender como, ao longo do tempo, o conhecimento científico foi modificado. Nesse sentido: 
não é uma coisa isolada de todas as outras, mas sim faz parte de um desenvolvimento histórico, de uma cultura, de um mundo humano, sofrendo influências e influenciando por vezes muitos aspectos da sociedade (MARTINS, 2006, p. XVII).

Ao trazer à tona esse aspecto, Lis aponta para uma questão importante no ensino, que é a necessidade de proporcionar aos alunos a contextualização da evolução dos conceitos de saúde que foram sofrendo influências das condições sociais, históricas e políticas ao longo dos anos, e ganhando novos entendimentos na comunidade científica e médica.

Ao recordar como os temas de saúde foram desenvolvidos na escola, Lúcia destaca a superficialidade nas explicações dos conteúdos, além de sentir falta de o (a) professor (a) trazer para o espaço escolar profissionais da área da saúde, ao explicitar que não havia ajuda de profissionais.

Para encontrar pistas que ajudem a refletir sobre a questão ora mencionada, apresento, ainda, duas passagens dos Diários de Bordo (DB) das licenciandas (Lia e Laura). Lia (DB, 2016) refletindo sobre o desenvolvimento da educação em saúde na escola, escreve "acho que uma forma de trabalhar seria chamando um médico e uma psicóloga e eles explicarem a partir dos 'sentimentos' dos próprios alunos". Laura (DB, 2016) apresenta outro ponto de vista: depois de termos assistido três filmes para discutir sobre Educação em Saúde, fico pensando como sempre há espaço e necessidades para mais aprendizados. Como sabemos e desenvolvemos tão pouco sobre saúde na escola. Para qualquer coisa relacionada à saúde, na escola, chamamos um médico? Um enfermeiro? Será que temos medo de não saber responder? E ainda fico pensando que há muito que aprendermos sobre Educação em Saúde.

As colocações das licenciandas aproximam-se e distanciam-se quanto à abordagem da Saúde e da Educação em Saúde na escola pelos professores e pelos profissionais da área da saúde. Por um lado, Lia e Laura consideram importante que esses profissionais contribuam com as discussões no ambiente escolar; por outro, Laura questiona a inserção, deixando nas entrelinhas que a presença dos profissionais da saúde atestaria de certa forma a incapacidade de o professor trabalhar com tal assunto.

A escrita de Laura, evidencia que ela não alcançou o significado esperado do papel do professor, pois não percebeu a necessidade da mediação, que, ao convidar outros profissionais para trabalhar questões de saúde, o professor é fundamental no 
processo. Após a intervenção destes profissionais, o professor deve fazer a mediação, que é essencial para que os conceitos apresentados pelos especialistas da saúde sejam ressignificados pelos estudantes. A mediação do professor neste processo proporciona a significação dos conceitos (VIGOTSKI, 2008).

Se o desenvolvimento da ES se constitui numa ação educacional intencional e deliberada, que tem como objetivo proporcionar ao sujeito conhecimentos basilares e autonomia na busca de novos conhecimentos sempre que desejar (MOHR, 2002), é fundamental a ação mediadora e intencional do professor de maneira a auxiliar e orientar na realização das operações intelectuais de forma conjunta e compartilhada.

A categoria seguinte apresenta os filmes como um instrumento pedagógico que possibilita refletir diferentes conhecimentos e questões curriculares.

ii) filmes comerciais como instrumento de reflexões sobre questões curriculares no processo formativo

Os filmes são instrumentos que viabilizam inúmeras discussões e também podem gerar debates articulados (NAPOLITANO, 2009). No episódio 03, procurei estabelecer relações entre a ES e os Temas Transversais. Para a construção do referido episódio, selecionei turnos dos registros da discussão do filme "O jardineiro fiel" (4 sessão fílmica), em que identifiquei assuntos tais como: questões de preconceito, gênero e sexualidade. "Em princípio, todos os filmes - "comerciais" ou "artísticos", ficcionais ou documentais - são veículos de valores, conceitos e atitudes tratados nos Temas Transversais" (NAPOLITANO, 2009, p. 20).

Episódio 03 - Filme: instrumento para tomada de consciência das questões socioculturais

Helena: [...] que tipo de aluno eu estou formando e que tipo de sujeito cidadão vai estar preparado a tomar uma decisão lá na vida real dele, a participar ou não de uma pesquisa, por exemplo? É uma questão de educação, é nossa.

Hugo: Posso fazer um adendo? Qual é o conceito de biologia? Vida! Estudo da vida? Que valor tem a vida humana para nós? Se a gente pode descartar pessoas por elas terem cor diferente, por elas estarem em condições econômicas em desvantagem da nossa. Que valor tem a vida humana? E outra, um pulo além, que valor tem um sentimento, será que essas pessoas não carregam um sentimento? Claro que carregam.

Luna: Eu gostaria de falar também uma coisa que notei. O valor da mulher também, quando ela falou que ia fazer sexo com ele, muita gente aqui atrás

Recebido em: 26/08/2020

Aceito em: $1 \% / 12 / 2020$ 
comentou, é uma vagabunda, casada. Usou o sexo para manipular, e isso também está na carta que o cara escreveu, a piranha, eu também achei o valor da mulher no filme.

Letícia: Acho que ele também era casado.

Luna: E se fosse o cara casado, e usasse o sexo o que seria comentado?

Pesquisadora: E tem toda a violência com a mulher apresentada durante o filme. Quantas foram estupradas e usadas na invasão final? São muito complexas todas as questões que esse filme pode trazer.

Luna: Me deu um certo... a mesma reação que você, porque eu estava bem no fundo e vi que alguns ironizavam né, tipo, vagabunda. Mas, ninguém se deu conta que ela estava usando a última arma que ela tinha para parar de matar um milhão de pessoas talvez, ela estava disposta, claro que depois, ela disse que não estava tão disposta assim! Mas, no final das contas ela estava disposta a sacrificar o corpo em nome da vida de outras pessoas, era essa a razão dela.

Sabrina: Pode-se levantar pra debates com os alunos no momento do filme essa questão de gênero, das diferenças de gênero.

Heitor: A homofobia. O médico por ser gay, ele foi castrado, crucificado, só por conta da orientação sexual, que lá é proibido. Acho que até hoje alguns países da África é proibida a orientação sexual diferente.

Sara: No seminário integrado, se é possível ou não, eu trabalho com seminário integrado e até agora os dois projetos que desenvolvi na escola iniciaram com filmes [...]. Então eu acho que esse filme, o jardineiro, sim, é possível utilizá-lo nos seminários integrados e abordar assuntos que tem a ver com os alunos, e se torna até mais fácil você fazer o trabalho do seminário a partir de um filme.

Sabrina: Por que muitas vezes a partir de um filme, você consegue abrir um caminho, uma sensibilização no aluno necessária para ti fazer depois a abordagem sobre determinado tema que tu deseja apresentar.

A discussão sobre Saúde e o desenvolvimento de atividades pedagógicas vão ganhando novas configurações, no discurso dos professores, ao extrapolarem a dimensão biológica do processo saúde-doença e promovem uma discussão que perpassa questões socioculturais propostas nos eixos temáticos dos Parâmetros Curriculares Nacionais (PCN), que juntamente com a Lei de Diretrizes e Bases - LDB n 9.394/96, tornaram-se a principal referência para a organização da educação formal no Brasil (BOMFIM et al. , 2013). Os PCN têm como objetivo abordar, na escola, problemáticas sociais, a partir da transversalidade entre temas e áreas curriculares, assim como em todo o convívio escolar (BRASIL, 1996).

Os turnos contidos no episódio 03 indicam pensamentos complementares entre os professores sobre a necessidade de uma abordagem contextualizada e com enfoque em questões sociais e próximas da realidade dos alunos ao abordar a Saúde. O filme como instrumento mediador provocou-os a pensarem e externalizarem seus sentimentos e compreensões sobre assuntos como: gênero e saúde, violência contra a mulher,

Recebido em: 26/08/2020

Aceito em: $1 \% / 12 / 2020$ 
discriminação social. Esses assuntos são propostos nos Temas Transversais dos PCN da área das Ciências da Natureza, porém pouco trabalhados no contexto escolar; e quando o são, é numa perspectiva biomédica de saúde.

Educar para a saúde parte da premissa de uma abordagem que contemple a saúde na perspectiva de promoção e qualidade, correlacionando a saúde aos seus determinantes (condições de moradia, renda, transporte, lazer, escolaridade, alimentação, acesso a bens e serviço de saúde) para que dessa forma os sujeitos possam ter atitudes e práticas seguras quanto à saúde individual e coletiva.

À medida que o grupo está mais imerso no processo de assistir e debater os filmes, novos sentidos e significados são dados a esse instrumento, que possibilitam outro pensar sobre a prática pedagógica. As professoras supervisoras Sara e Sabrina, ao referirem que os filmes estavam sendo utilizados nos projetos de ensino da escola (Seminário Integrado), apontam um excelente meio para articular e iniciar a abordagem de determinados assuntos polêmicos, que geram diferentes emoções e pontos de vista nos alunos. A partir dessas reflexões e dos diálogos estabelecidos vou identificando transformações na forma dos professores em formação, refletirem sobre Saúde, ES e utilização de filmes, na sala de aula.

Concordo com Güllich (2013, p. 187), quando afirma que "no grupo recriam-se as condições sociais da profissão docente pela verbalização dos sentidos sociais que, ao estarem em disputa, são também (re)significados no e pelo grupo”. Este episódio trouxe à tona situações formativas e olhares mais atentos para o processo de ensino e saberes constitutivos para uma aprendizagem de cidadania pautada na consciência e prática de direitos e deveres, na perspectiva do bem comum. Na próxima categoria, serão abordadas as questões referentes a produção do conhecimento científico, a visão de Ciência e a ética nas pesquisas científicas. Com base nesta categoria afirmo a tese que os filmes comerciais possibilitam ao grupo formativo novos entendimentos e compreensões sobre Saúde e ES, entre outros temas correlatos ao ensino das Ciências da Natureza.

iii- A produção do conhecimento científico e ética na pesquisa 
Para que professores e estudantes compreendam a Ciência como uma produção humana em constante transformação, impregnada de valores e mudanças sociais (SANTOS; LEITE, 2014), é importante que durante o processo formativo a abordagem desta temática seja mais pontual, pois, no momento em que esses conhecimentos são tratados numa perspectiva histórica e não linear, os alunos têm a possibilidade de compreender as condições sociais, históricas e políticas que influenciaram o desenvolvimento da Ciência, e, em particular, da saúde, como indica Scliar (2007). Assim, para contextualizar a emergência desta discussão no espaço escolar, apresento o episódio (04), que trata da produção do conhecimento científico e da ética nas pesquisas. Essas temáticas apareceram nas discussões da terceira sessão do fílmica "O óleo de Lorenzo".

Episódio 04 - Reflexões sobre a produção do conhecimento científico e a ética nas pesquisas

Selma: uma coisa que daria para chamar a atenção das crianças na aula é para a maneira que os pesquisadores, os cientistas trabalham. Que não é tão fácil assim, [...] como trabalha o cientista, como eles buscam. Eu acho bacana também, porque eles não têm ideia lá no ensino fundamental né, como é que um cientista trabalha, como é que eles fazem.

Lia: os cientistas, eles competem, né! Dá para ver bem, que um não queria, pois, quando vê que o outro poderia encontrar a cura e ter seu nome reconhecido, então sei lá.

Luíza: Mas eu acho que no simpósio eles falaram que iam publicar um livro de receitas, eles não estavam preocupados com a cura, eles estavam preocupados em manter aquele quadro que tinham que a pesquisa tinha chegado.[...] quando os pais indagaram eles (médicos) falaram de tudo, então os médicos disseram que eles não tinham comprovação científica, foram só contra, não é testado, não pode, é contra a ética...

Pesquisadora: Pensando na questão de saúde e a questão ética envolvida (interrupção pela intervenção de Letícia).

Letícia: Ali, foi graças a um trabalho não ético que foi descoberta ou encontrada uma forma de amenizar os sintomas (referindo-se aos sintomas da adenoleucodistrofia).

Heitor: Mas será que não é ético, né?

Pesquisadora: Mas analisando a situação, qual grupo está sendo menos ético?

Heitor: Eu acrescentaria a pergunta [...] mas, porque não era ético?

Luíza: Não é ético pela visão dos médicos, que tem que ter ah, liberações ou autorizações.

Pesquisadora (3a SF, T19, 2016): Ah, tá, do ponto de vista do protocolo de pesquisa.

Recebido em: 26/08/2020

Aceito em: $1 \% / 12 / 2020$ 
Luíza: É porque os médicos foram contra né, falaram que não poderiam estar distribuindo o óleo para aquele menino que tinha adenoleucodistrofia,[...] então pelo ponto de vista daquela sociedade, né.

A participação dos professores no grupo colaborativo possibilitou novos entendimentos e reflexões sobre diferentes temas, como: as finalidades da Ciência, os estereótipos de cientistas, a ética na pesquisa científica, o direito à vida e à morte, em decorrência da diversidade de pensamentos em movimento.

As três categorias, apresentam a evolução da significação de conceitos em Saúde e Educação em Saúde do grupo de professores que participaram do processo formativo. À medida que as interações e discussões foram avançando, o grupo pôde compreender que conhecimentos em Saúde são um patrimônio cultural ao qual devem ter acesso as novas gerações de forma sistemática e intencional, o que acontece na Escola. A complexidade cultural nesta área é tão grande que não bastam práticas e recomendações do cotidiano para a formação hoje necessária, desta forma, é importante repensarmos a maneira como ensinamos e educamos para a saúde no espaço escolar.

Há de se enfatizar que no decorrer do processo, como é evidenciado nas três categorias, os professores foram analisando e refletindo sobre sua docência, ressignificando e tomando consciência de seus conhecimentos sobre Saúde e ES e sua prática pedagógica a partir da mediação da pesquisadora e do instrumento pedagógico filme. As marcas deste processo vivenciado são a mediação, a reflexão, a interação e a constituição pelo outro, fatores que potencializaram e contribuíram com o desenvolvimento profissional do grupo de professores.

\section{CONSIDERAÇÕES FINAIS}

Este estudo mostra que a participação no grupo proporcionou aos professores envolvidos um espaço e tempo para discutir várias temáticas referentes à professoralidade, e refletir sobre a prática em relação ao desenvolvimento da temática saúde em sala de aula. E, principalmente, a compreensão inicial do pouco ou nenhum conhecimento das abordagens de saúde (biomédico, comportamental, biopsicossocial, ecossistêmico) que os professores envolvidos tinham. No início do processo de investigação, os professores em formação (licenciandos e supervisores) compreendiam a saúde, apenas como ações preventivas, com ênfase em saberes tecnocientíficos.

Recebido em: 26/08/2020

Aceito em: $1 \% / 12 / 2020$ 
A partir da análise do processo vivenciado, percebi que no grupo formativo ocorreram de forma lenta e gradual novas compreensões do conceito de saúde provocadas pelos filmes, que aguçaram o olhar dos participantes. E é partir deste sentido que identifiquei, nos filmes, um instrumento com capacidade de mobilização das funções superiores dos sujeitos participantes da investigação. O processo de mediação e interação entre os pares promoveu a tomada de consciência dos professores e a necessidade de ampliar o seu entendimento de saúde. A discussão no coletivo e a intervenção do outro foram fundamentais para que os sujeitos aprendessem um novo conceito num nível de maior generalidade, que contempla as questões ambientais, culturais, de conhecimentos e valores dos sujeitos. A ES não se resume a prover informações "corretas" aos alunos, mas em problematizar os conceitos e significados atribuídos por eles na sua família e comunidade com as explicações científicas existentes e as novas.

\section{REFERÊNCIAS}

ALARCÃO, I. Professores reflexivos em uma escola reflexiva. 8. ed. São Paulo: Cortez, 2011.

ANTUNES, J. P. Para além das palavras. In: ZANCUL, M. C. S.; BADIA, D. D.; VIVEIRO, A. A. (Orgs.). Cinema e educação: algumas leituras possíveis. São Paulo: Cultura Acadêmica, 2015. p. 9-12.

BARDIN, L. Análise de Conteúdo. Lisboa, Portugal; Edições 70, LDA, 2004.

BOMFIM, A. et al. Parâmetros curriculares nacionais: uma revisita aos temas transversais meio ambiente e saúde. Trabalho, Educação e Saúde, v. 11, n. 1, jan./ abr., 2013. $27-52$ p. Disponível em: <http://www.scielo.br/scielo.php?script=sci_abstract\&pid=S 198177462013000100003 \&lng=pt\&nrm=iso\&tlng=pt>. Acesso em: 11 jun. 2016.

BRASIL. Lei n 9394/1996. Lei de Diretrizes e Bases Nacionais da Educação, 1996.

Parâmetros Curriculares Nacionais: Terceiro e Quarto Ciclos: Apresentação dos Temas Transversais. Ministério da Educação. Secretaria de Educação Fundamental. Brasília, DF, 1997.

CARVALHO, G. S.; JOURDAN, D. Literacia em Saúde na Escola: a importância dos contextos sociais. In: JÚNIOR, C. A. O. M.; JÚNIOR, A. L.; CORAZZA, M. A. (Orgs.). Ensino de Ciências: múltiplas perspectivas, diferentes olhares. Curitiba: CRV, 2014. p. 99-122.

CHAVES, S. N. História da Ciência Através do Cinema: dispositivo pedagógico na formação de professores de ciências. Alexandria Revista de Educação em Ciência e Tecnologia, Florianópolis, v. 5, n. 2, set., 2012. p. 83-93. Disponível em: $<$ https://periodicos.ufsc.br/index.php/alexandria/article/view/37715/28889>. Acesso em: 09 jul. 2015.

Recebido em: 26/08/2020

Aceito em: $1 \% / 12 / 2020$ 
DUARTE, R. et al. Produção de sentido e construção de valores na experiência com o cinema. In: SETTON, M. G. J. (Org.). A cultura da mídia na escola: ensaios sobre cinema e educação. São Paulo: Annablume, 2004. p. 37-52.

FREITAS, A. P. Zona de Desenvolvimento Proximal: a problematização do conceito através de um estudo de caso. 2001. 137 f. Tese. (Doutorado em Educação), Universidade Estadual de Campinas, Campinas.

GARCÍA, C. M. A formação de professores: novas perspectivas baseadas na investigação sobre o pensamento do professor. 1992. In: NÓVOA, A. Os professores e a sua formação. 2. ed. Portugal: Editora Porto, 1995. p. 51-75.

GOES, M. C. R. A abordagem microgenética na matriz histórico-cultural: Uma perspectiva para o estudo da constituição da subjetividade. Cadernos CEDES, Campinas, v. 20, n. 50, abr. 2000. p. 25-29. Disponível em: <http://www.paulorosa.docente.ufms.br/metodologia/Goes_Analise_microgenetica.pdf> . Acesso em: 12 fev. 2014.

GÜLLICH, R. I. C. Investigação-Formação-Ação em Ciências: um caminho para reconstruir a relação entre livro didático, o professor e o ensino. Curitiba: Editora Appris, 2013.

GUSTAVO, L. S.; GALIETA, T. A Educação em Saúde está contemplada na formação inicial de professores de Ciências Biológicas? Revista da REnBIO, São Paulo, n. 7, out. $2014 . \quad$ p.4877-4889. Disponível em: http://www.sbenbio.org.br/wordpress/wpcontent/uploads/2014/11/R0209-1.pdf. Acesso em: 13 jun. 2016.

IMBERNÓN, F. Formação permanente do professorado: novas tendências. São Paulo: Cortez, 2009.

KNAUT, V. T.; PONTAROLO, A. R.; CARLETTO, M. R. Educação em saúde, Ensino de Ciências e Formação de professores. In: IX Encontro Nacional de Pesquisa em Educação em Ciências (IX ENPEC). n. 15, 2013, Águas de Lindóia, Atas... Águas de Lindóia: ABRAPEC, 2013. p. 1-8.

MALDANER, O. A. Formação Inicial e Continuada de Professores de Química: professor pesquisador. 4. ed. Ijuí: Editora Unijuí, 2013.

MARTINS, L. Abordagens da saúde em livros didáticos de biologia: análise crítica e proposta de mudança. 2017. 165 f. Tese. (Doutorado em Educação) Ensino, Filosofia e História das Ciências. Universidade Federal da Bahia, Bahia.

MARTINS, R. A. Introdução: A História das Ciências e seus usos na Educação. In: SILVA, C. C. (Org.). Estudos de História e Filosofia das Ciências: subsídios para aplicação no ensino. São Paulo: Editora Livraria da Física, 2006. p. XVII-XXX.

MOHR, A. A natureza da educação e saúde no Ensino Fundamental e os professores de ciências. 2002. 409 f. Tese. (Doutorado em Educação) Programa de Pós-Graduação em Educação, Centro de Ciências da Educação, Universidade Federal de Santa Catarina, Florianópolis.

MONTEIRO, P. H. N.; BIZZO, N. A saúde na escola: análise dos documentos de referência nos quarenta anos de obrigatoriedade dos programas de saúde, 1971-2011. História, Ciências, Saúde - Manguinhos, Rio de Janeiro, v. 22, n. 2, abr./jun. 2015. p.

Recebido em: 26/08/2020

Aceito em: $1 \% / 12 / 2020$ 
411-427. Disponível em: <http://www.scielo.br/pdf/hcsm/v22n2/0104-5970hcsm2014005000028.pdf>. Acesso em: 27 abr. 2016.

NAPOLITANO, M. Como usar o cinema na sala de aula. 2. ed. São Paulo: Contexto, 2013.

Cinema: experiência cultural e escolar. In: TOZZI, Devanil. (org.). Caderno de cinema do professor II. 2. ed. São Paulo: FDE, 2009. p. 10-31.

NÓVOA, A. Os professores e sua formação. Trad. Graça Cunha, Cândida Hespanha, Conceição Afonso e José António Souza Tavares. 2. ed. Lisboa: Instituto Inovação Educacional, 1995.

PINO, A. As marcas do humano: às origens da constituição cultural da criança na perspectiva de Lev S. Vigotski. São Paulo: Cortez, 2005.

REGO, T. C. Vygotsky: uma perspectiva histórico-cultural da educação. Petrópolis: Vozes, 1995.

REIS, R. H. A constituição do sujeito político, epistemológico e amoroso na alfabetização de jovens e adultos. 2000. 267 f. Tese. (Doutorado em Educação), Faculdade de Educação, Universidade Estadual de Campinas, Campinas.

REZENDE-FILHO, L.A.C; PEREIRA, M.V.; VAIRO, A. C._Recursos Audiovisuais como temática de pesquisa em periódicos brasileiros de Educação em Ciências. Revista Brasileira de Pesquisa em Educação em Ciências, v, 11, n. 2, 2011.

ROMANELLI, O. História da Educação no Brasil: (1930/1973). Petrópolis: Vozes, 2007.

RUDEK, K.; SANTOS, E.G. Possíveis abordagens de saúde nos enredos de filmes comerciais. Revista da REnBio, Niterói, v. 9, dez. 2016. p. 4161-4173.

SABOGA-NUNES, L. A. et al. Níveis de alfabetização/literacia para a saúde em duas populações de diferentes níveis de escolaridade na construção da cidadania. In: BOFF, E.T.O.; ARAÚJO, M.C.P.; CARVALHO, G.S. (Orgs.). Interações entre conhecimentos, valores e práticas na Educação em Saúde. Ijuí: Editora Unijuí, 2016. p. $57-88$.

SABOGA-NUNES, L.; SORENSEN, K. The European Health Literacy Survey (HLSEU) and its Portuguese Cultural Adaptation and Validation (HLS-PT). Aten Primaria. 2013. p. 45-46.

SANTOS, E. G.; LEITE, F. A. Epistemologias, Narrativa e Formação Docente. Revista da REnBio, v. 7, 2014. p. 1743-1754.

SANTOS, J. L. F.; WESTPHAL, M. F. Práticas emergentes de um novo paradigma de saúde: o papel da universidade. Estud. av. vol.13 no.35, São Paulo Jan./Abr. 1999. Disponível em: <http://dx.doi.org/10.1590/S0103-40141999000100007>. Acesso em: 16 mai. 2017.

SCHALL, V. T.; STRUCHINER, M. Educação em Saúde: novas perspectivas. Cadernos de Saúde Pública, Rio de Janeiro, v.15, n. 2, 1999. p. 1.

SCHALl, V.T. Saúde \& Cidadania. In: Pavão, A.C (Org.). Coleção: Explorando o ensino de Ciências. v. 18, Brasília: MEC, SEB, 2010. p. 179-196.

Recebido em: 26/08/2020

Aceito em: $1 \% / 12 / 2020$ 


\section{SCHÖN, D.A. Educando o Profissional Reflexivo: um novo design para o ensino e a} aprendizagem. Trad. Roberto Cataldo Costa. Porto Alegre: Artmed, 1983.

SCLIAR, M. História do Conceito de Saúde. Saúde Coletiva. Rio de Janeiro, v. 17, n. 1, jan./ abr. 2007. p. 29-41. Disponível em: < http://www.scielo.br/pdf/physis/v17n1/v17n1a03.pdf>. Acesso em: 10 jun. 2015.

VENTURINI, T.; PEDROSO, I.; MOHR, A. Educação em Saúde na Escola a partir de uma perspectiva pedagógica: discussões acerca da formação de professores. In: VI Encontro Regional Sul de Ensino de Biologia - EREBIO-SUL, 6., 2013, Santo Ângelo. Anais... . Santo Ângelo: SBEnBio, 2013. p. 1-11. Disponível em: $<$ http://santoangelo.uri.br/erebiosul2013/anais/wpcontent/uploads/2013/07/comunicacao /13437_130_Tiago_Venturi.pdf>. Acesso em: 10 abr. 2016.

VIGOTSKI, L.S. Pensamento e Linguagem. 4. ed. São Paulo: Martins Fontes, 2008.

Manuscrito de $1929 . \quad$ Disponível em: <http://www.scielo.br/scielo.php?script=sci_arttext\&pid=S0101-73302000000200002>. Acesso em: 12 dez. 2015.

ZANCUL, M. S.; COSTA, S. S. Concepções de professores de Ciências e de Biologia a respeito da temática Educação em Saúde na escola. Experiências em Ensino de Ciências, Mato Grosso, v. 7, n. 2, ago. 2012. p- 67-75. Disponível em: < http://if.ufmt.br/eenci/artigos/Artigo_ID183/v7_n2_a2012.pdf>. Acesso em: 22 abr. 2016.

ZANCUL, M. S.; GOMES, P. H. M. A formação de licenciados em Ciências Biológicas para trabalhar temas de Educação em Saúde na escola. Revista Ensino, Saúde e Ambiente, Rio de Janeiro, v. 4, n.1, abr. 2011. p. 49-61. Disponível em: < http://ensinosaudeambiente.uff.br/index.php/ensinosaudeambiente/article/view/100> . Acesso em: 22 abr. 2016.

ZEICHNER, K. Uma análise crítica sobre a "reflexão" como conceito estruturante na formação docente. Educação e Sociedade, Campinas, v. 29, n.103, mai./ago. 2008. p. 535-554. Disponível em: 〈http://www.cedes.unicamp.br〉. Acesso em: 12 mai. 2016.

Recebido em: 26/08/2020

Aceito em: $1 \% / 12 / 2020$ 